\title{
USEFULNESS OF BIOFLAVONOIDS AND ASCORBIC ACID IN TREATMENT OF COMMON COLD
}

\author{
Harry E. Tebrock, M.D., New York, Joseph J. Arminio, M.D., Ossining, N. Y. \\ and \\ John H. Johnston, M.D., West Hartford, Conn.
}

\begin{abstract}
The objective evaluation of a new form of treatment for the common cold has always proved difficult. Since the viruses causing it have thus far completely resisted all attempts at direct annihilation through the use of antibiotics, no bacteriological studies on the disappearance of the causative organism have proved feasible, nor have any other laboratory tests been found of great use in estimating the individual's rate of recovery. Therefore, the evaluation necessarily has been based essentially on clinical observations.
\end{abstract}

Basically, treatment of the common cold has been limited to the relief of symptoms, the prevention of complications, and the general and specific supportive therapies that enable the body's own defense mechanisms to overcome the disease. Because the illness is essentially self-limited, with serious complications developing in only a small proportion of cases, any therapy that alleviates the patient's symptoms is called a cure until the test of time reduces it to the level of the other drugs that make the patient more comfortable but do not appreciably affect the underlying cause of the disease. To postulate that a given drug has a specific effect upon the disease, therefore, it must be shown that it does more than relieve symptoms. It should shorten the course of the illness. Furthermore, since there are innumerable drugs that make the patient more comfortable and alleviate symptoms, thereby creating subjective evidence that they are affecting the course of the cold, a cold cure should have an effect over and above the best of these relief medications. Lastly, in view of the fact that the evaluation of effect is almost entirely clinical, and therefore subjective from the point of view of either the patient or the observer, the beneficial result of the drug should be demonstrable in a controlled experiment in which personal bias has been entirely eliminated.

In the past decade, much attention has been given to the treatment of colds by the use of drugs that would enhance the body tissue's resistance to invasion. This has been at least in part behind the rationale for the use of such agents as antihistamines. ${ }^{1}$ Even more recently, the administration of ascorbic acid (vitamin C) has been advocated, ${ }^{2}$ both to raise the general resistance and on the theory that viral invasion is a function of capillary wall permeability that could be reduced by raising the ascorbic acid levels in the blood. On the basis of this theory, ascorbic acid has been added to a number of preparations used for the treatment of acute upper respiratory infections. The most recent approach to the problem has been an extension of this theory. It has been noted that the citrus bioflavonoids enhance the effect of ascorbic acid

Medical Director, Sylvania Electric Products, Inc. (Dr. Tebrock) and Medical Director, Pratt-Whitney and Company, Inc., West Hartford, Conn. (Dr. Johnston).

\begin{abstract}
- The evaluation of any drug used to treat the common cold must necessarily be based on clinical observations. Bioflavonoids and ascorbic acid, singly and in combination, were evaluated in a study on almost 2,000 persons as to their efficacy, not by symptom alleviation but as to whether it would shorten the course of illness. The overwhelming impression gained from the study presented is the singular lack of effect in altering the course of the common cold by either the bioflavonoid or the ascorbic acid.
\end{abstract}

in maintaining or restoring to normal the integrity of the capillary wall. ${ }^{3}$ In particular, they have been reported as directly combating virus infections by preventing the micro-organisms from penetrating the capillary endothelium. It has been logically argued, therefore, that the bioflavonoids can exert a beneficial effect on the body's ability to resist the invasion of respiratory viruses, and several observers have reported cases that appear to substantiate this claim. ${ }^{4}$ Because of the widespread interest in this attack on the problem of the common cold, it was felt that a definitive test of these agents would be of considerable value.

Since it is admitted that neither ascorbic acid nor the bioflavonoids have any in vitro effect on respiratory viruses, ${ }^{7}$ such a study would have to be entirely clinical. It would be necessary to prove either that an appreciable number of colds were aborted in their early stages or that some or all of the symptoms were cleared up significantly earlier. The effect looked for would be more than a temporary alleviation of symptoms and should therefore be demonstrable even in the presence of other medicaments given merely to that end. To avoid any possibility of observer bias, the trials should be made on a completely blind basis.

\section{Methodology}

Since the bioflavonoids were postulated as acting in conjunction with ascorbic acid, it was felt necessary to study the effect of the two substances both singly and in combination. An experimental design was used that would permit the evaluation of each compound independently and also would demonstrate any synergistic effect obtained. The trials were therefore conducted with the following four preparations: (1) $250 \mathrm{mg}$. of bioflavonoid (lemon bioflavonoid complex 497, Sunkist Growers) plus $50 \mathrm{mg}$. of ascorbic acid; (2) 250 mg. of bioflavonoid; (3) $50 \mathrm{mg}$. of ascorbic acid; and (4) placebo.

The subjects were divided into four groups, each of which was given one of these preparations four times a day. In order to demonstrate that any effect ob- 
served was more than that obtainable through standard palliative practice, every patient received a preparation containing $325 \mathrm{mg}$. of salicylamide, $195 \mathrm{mg}$. of acetophenetidin, $65 \mathrm{mg}$. of caffeine, and $50 \mathrm{mg}$. of thonzylamine hydrochloride. This was done so that a patient not receiving ascorbic acid or bioflavonoid or a combination was actually receiving medication, which, in addition, acted as a control. ascorbic acid will be demonstrated using all the patients, since the two halves represent the same distribution except for the presence or absence of this factor. The patients indicated in the lower box of each half also receive bioflavonoid, but, since they are about the same proportion of the total, the effect of the latter will cancel out unless a marked synergism is present. The difference produced by bioflavo-

\begin{tabular}{|c|c|c|c|c|c|c|c|c|c|c|c|c|c|c|c|c|}
\hline \multirow{4}{*}{$\begin{array}{l}\text { Sex } \\
\text { Male } \\
\text { Femnle }\end{array}$} & \multicolumn{2}{|c|}{$\begin{array}{c}\text { Group 1 } \\
\text { Without } \\
\text { FInvonoid } \\
\text { or } \\
\text { Ascorble Acid }\end{array}$} & \multicolumn{2}{|c|}{$\begin{array}{c}\text { Group }= \\
\text { With } \\
\text { Foronoid } \\
\text { \&nd } \\
\text { Ascorbic Acid }\end{array}$} & \multicolumn{2}{|c|}{$\begin{array}{c}\text { Group } 3 \\
\text { Without } \\
\text { Flay'onold } \\
\text { and Witb } \\
\text { Ascorbic Aeld }\end{array}$} & \multicolumn{2}{|c|}{$\begin{array}{c}\text { Group } 4 \\
\text { With } \\
\text { Flayonoid } \\
\text { and Wilthout } \\
\text { Ascorbic Acld }\end{array}$} & \multicolumn{2}{|c|}{$\begin{array}{c}\text { Groug j } \\
\text { Without } \\
\text { Flavonold } \\
\text { or } \\
\text { Aseorbic Aeld }\end{array}$} & \multicolumn{2}{|c|}{$\begin{array}{c}\text { Group } 6 \\
\text { With } \\
\text { Fl \#ronold } \\
\text { and } \\
\text { dscorbic Add }\end{array}$} & \multicolumn{2}{|c|}{$\begin{array}{l}\text { Group } \\
\text { Wtth } \\
\text { Flayonoid } \\
\text { Rad Without } \\
\text { Ascorbic dcid }\end{array}$} & \multicolumn{2}{|c|}{$\begin{array}{l}\text { Grout s } \\
\text { Without } \\
\text { Flaronoid } \\
\text { and With } \\
\text { Ascorbtc Acid }\end{array}$} \\
\hline & so. & $\%$ & So. & $\%$ & No. & $\%$ & No. & $\%$ & Yo. & $\%$ & No. & $\%$ & No. & $\%$ & No. & 5 \\
\hline & 134 & 59.2 & 188 & 60.8 & 144 & 55.2 & 134 & $\Delta .0$ & 129 & {$[5,6$} & 136 & $\overline{150.7}$ & 193 & 49.8 & 126 & 52.5 \\
\hline & 118 & 46.8 & 91 & 39.7 & 117 & 44.8 & 110 & 45.1 & 110 & 43.0 & 105 & 44.3 & 123 & 30.2 & 114 & $47 . \tilde{a}$ \\
\hline Co to 20 & 18 & & 11 & & 10 & & 16 & & 11 & & 7 & & 13 & & 18 & \\
\hline $91-95$ & 38 & & $4 \pi$ & & 37 & & 45 & & 49 & & 49 & & 41 & & 42 & \\
\hline$\because 6-30$ & $\$ 7$ & & 49 & & 67 & & 57 & & 00 & & 70 & & 62 & & 30 & \\
\hline $31-8 ;$ & 64 & & 48 & & 45 & & 46 & & 4 & & $\$ 1$ & & 14 & & 57 & \\
\hline 36.40 & 32 & & 27 & & 14 & & 34 & & 24 & & 24 & & 32 & & 25 & \\
\hline +1-1: $\overline{1}$ & 38 & & גi & & 29 & & 23 & & 29 & & 28 & & 31 & & 20 & \\
\hline$\sqrt{16-50}$ & 13 & & 8 & & 8 & & 10 & & 12 & & 9 & & 10 & & 10 & \\
\hline $31-\bar{x}$ & 10 & & 5 & & 8 & & 0 & & 7 & & 14 & & 4 & & 8 & \\
\hline Total & $\overline{24 i}$ & & $\overrightarrow{22 I}$ & & 259 & & $\overline{342}$ & & 284 & & $2 \overline{i n}$ & & 242 & & 237 & \\
\hline Mean age & 34.0 & & 33.0 & & 34.2 & & 9a.s & & 32.8 & & 33.9 & & 83,2 & & $\$ 8.0$ & \\
\hline $\begin{array}{l}\text { Mpan no. of } \\
\text { colils per yr. }\end{array}$ & 2.65 & & 2.72 & & 2.72 & & 2,78 & & 2.33 & & 9.51 & & 2.99 & & 2.34 & \\
\hline
\end{tabular}

Use of these four preparations enables one, by means of a square experimental design, to simultaneously compare the effect of two drugs, both separately and together, and yet to use all the patients in each of the comparisons. In figure 1, each of the boxes represents an approximately equal number of patients receiving the drugs indicated. The effect of

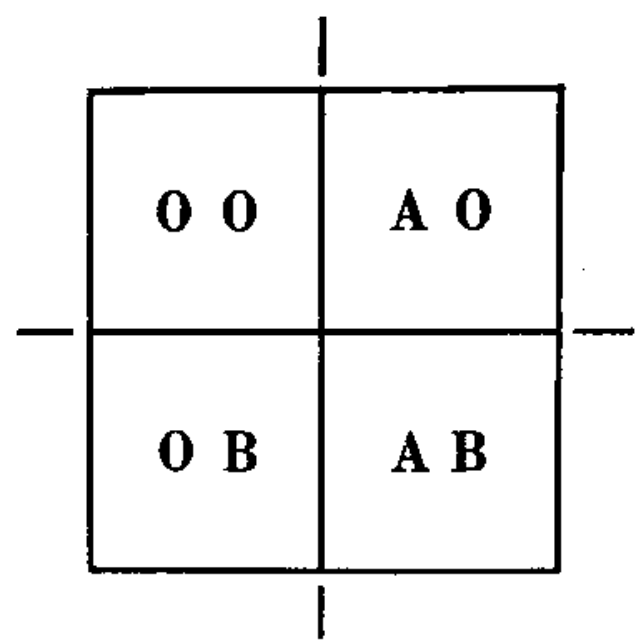

Fig. 1. - Diagram of square experimental design. $\mathrm{O}=$ placebo; $\mathrm{A}=$ ascorbic acid; and $\mathrm{B}=$ bioflavonoid.

ascorbic acid (A in fig. 1) could be evaluated by comparing the upper two boxes and that of bioflavonoid ( $\mathrm{B}$ in fig. 1) could be evaluated by comparing the two left-hand ones, but this would utilize only half the patients for each evaluation. If, however, the patients in the left-hand side of the square are compared with those in the right-hand half, the effect of noid, irrespective of ascorbic acid, can be shown similarly by comparing the upper and lower halves. The amount of synergism or antagonism can be evaluated by determining whether the difference between $\mathrm{OO}$ (placebo) and $\mathrm{AB}$ is significantly greater or less than the sum of the difference between $\mathrm{OO}$ and $\mathrm{AO}$ plus $\mathrm{OO}$ and $\mathrm{OB}$.

The trials were conducted on subjects reporting to several outpatient industrial clinics under the supervision of the physicians conducting the study. A num-

TABLE 2.-Additional Diagnoses and Other Medications in Drug Groups

\begin{tabular}{|c|c|c|c|c|c|c|c|c|c|}
\hline \multirow{3}{*}{$\begin{array}{l}\text { Additionul } \\
\text { Dfrknoseg }\end{array}$} & \multicolumn{4}{|c|}{ Flнبonoid } & & \multicolumn{4}{|c|}{ Ascorbic Acld } \\
\hline & \multicolumn{2}{|c|}{ with } & \multicolumn{2}{|c|}{ Without } & \multirow{2}{*}{$\therefore$} & \multicolumn{2}{|c|}{ With } & \multicolumn{2}{|c|}{ Without } \\
\hline & No. & $\%$ & so. & $\%$ & & No, & $\%$ & No. & $\%$ \\
\hline Tracheobronchitis & 42 & 4.4 & $8 \pi$ & 8.5 & & 192 & 4.4 & $3 i$ & $3, \mathbf{y}$ \\
\hline Antlbiotic glyen & 69 & 7.8 & 69 & 6.5 & & $\pi$ & 7.4 & 61 & 6.4 \\
\hline Sasul decongest ant & $13 i$ & 14.2 & 138 & ]3.7 & & 139 & 13.9 & $13 \vec{r}$ & 14.1 \\
\hline Congh medicine & $\$ 9$ & 9.4 & 116 & 12.0 & & 902 & 9.6 & 113 & 11.8 \\
\hline Pjlls not all taken & $\stackrel{2031}{1}$ & $23 x$ & 200 & 20.6 & & 292 & 23.2 & 19 & 20.7 \\
\hline Total In group & $9+\vec{i}$ & & 90 & & & 256 & & g80 & \\
\hline
\end{tabular}

ber of college, seminary, and private patients of one of the authors were also included. Medicaments supplied to these physicians were identified only by number, so that neither they nor the patients were aware of what was being given. Furthermore, in order to reduce the possibility of the clinical judgments being influenced by continued association of better results with one of the preparations, each of them was supplied under two numbers, making eight test groups in all to which the patients were assigned in rotation. 
Because it was not feasible to reexamine the subjects daily, a single checkup after three days was decided on. It was felt that, if colds were aborted to any appreciable degree by one or both of the drugs, the number of cures after three days should be appreciably higher than in the controls. At the same time, while some alleviation of symptoms was expected in all groups, the proportion should be materially increased in any group receiving an effective therapeutic agent in addition to the palliative medicament. The three-day limit was selected because, with a longer interval, too many cases might resolve spontaneously, while a shorter time would not afford a chance for disappearance of symptoms even under effective therapy. Since the dispensaries were in operation from Monday through Friday, only those cases first seen on Monday, Tuesday, and Friday were included in the study, in order to permit a return at the proper time.

Patients coming to the dispensaries or private offices on those days were first examined. If a diagnosis of an acute upper respiratory infection was made, patients were admitted to the study and assigned to one of the eight test groups in sequence. Their symptoms, physical findings, and other pertinent data were then recorded on a special printed form, which was preceded for machine punching and tabulation. The patient was given sufficient medicament to provide four doses a day for three days and instructed to report back at the end of that time. To simplify compounding and dispensing the medicaments, the ingredients that varied from group to group were put into one capsule, while those given to all groups were put in another. Cough medicine and nasal decongestants were also dispensed if indicated and were recorded on the form. In the case of the industrial patient, when secondary bacterial infection appeared to be developing, he was recommended to his personal physician.

Symptoms to be recorded were limited to eight considered most characteristic of the common cold: running nose, sneezing, hoarseness, cough, malaise,

TABLE 3.-Subjective and Objective Change by Drug Groups

\begin{tabular}{|c|c|c|c|c|c|c|c|c|}
\hline \multirow[b]{3}{*}{$\begin{array}{l}\text { Cobange } \\
\text { iective }\end{array}$} & \multicolumn{4}{|c|}{ Biofayonoid } & \multicolumn{4}{|c|}{ Aseostie Arld } \\
\hline & \multicolumn{2}{|c|}{ With } & \multicolumn{2}{|c|}{ Whthout } & \multicolumn{2}{|c|}{ with } & \multicolumn{2}{|c|}{ Without } \\
\hline & No. & $\because$ & Sin. & $\because$ & ro. & $?$ & No. & 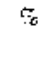 \\
\hline Worle & 110 & 11.7 & 12: & 12.5 & 111 & 11.6 & 11ㅣ & 12.6 \\
\hline So change & $\because 15$ & 28.7 & גו & $2: 2.3$ & i & 23.5 & 210 & 21.9 \\
\hline Improved & $40 x$ & 43,1 & tint & 41.1 & this & + \pm .7 & $3+i$ & 4]. \\
\hline curerd & $2 \mathrm{t}^{5}$ & $2: 2.1$ & $23 \mathrm{I}$ & 24.9 & 13 & 난.2 & \pm 20 & $\stackrel{23.9}{-3}$ \\
\hline Total & 142 & & $3 \div 3$ & & 9.5 & & 937 & \\
\hline Obiertive & & & & & & & & \\
\hline Worse & ig & 8.4 & $n$ & 9.5 & $8 i$ & $\S .9$ & Si & 0.1 \\
\hline So phange & $2(10$ & 21.3 & 159 & 19.5 & $=01$ & 21.2 & lEs & Ј9.6 \\
\hline Improved & $\$ \$ 1$ & 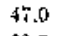 & $4 \$ 9$ & 46.2 & 448 & 40.6 & $44_{i}^{i}$ & 40.6 \\
\hline Cured & 319 & 38.2 & 949 & $24 . \overline{7}$ & 291 & 23.3 & 237 & 24.7 \\
\hline Total & 4333 & & $9 \bar{i} \mathrm{I}$ & & 250 & & 979 & \\
\hline
\end{tabular}

headache, postnasal drip, and sore throat. Only their presence or absence at the initial visit was noted, to avoid the difficulty of grading their severity. The time since the onset of the first symptoms was also recorded, as was the patient's temperature at the initial visit. The notation of physical findings was also limited to those associated with acute upper respiratory infections. Nasal secretions were reported as none, slight or marked, or mucoid or purulent and nasal obstruction as none, partial or complete, or unilateral or bilateral. Pharyngitis was graded as none, mild, moderate, or severe. The diagnoses of pharyngotonsillitis or tracheobronchitis were recorded if present.

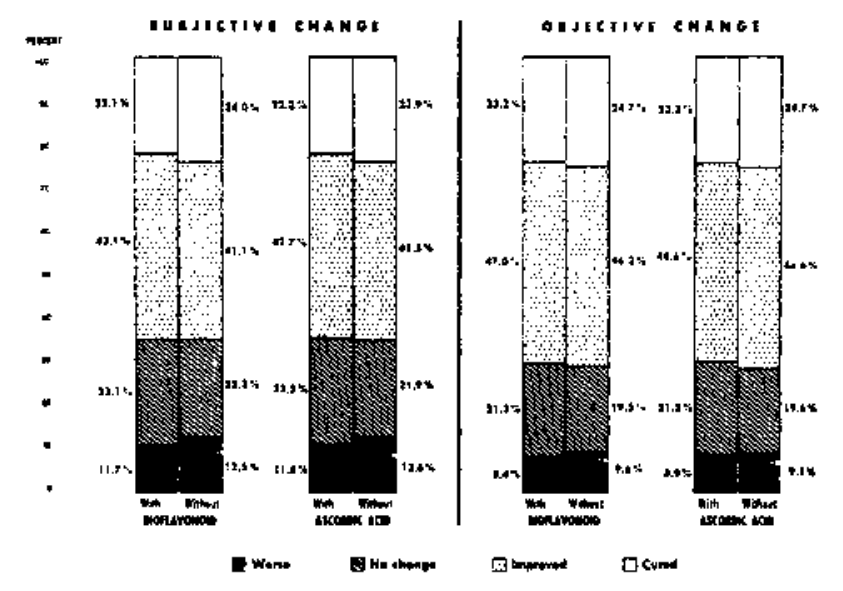

Fig. 2.-Subjective and objective change by drug groups.

At the examination on the third day, the presence or absence of the same symptoms was again recorded, and the physical findings were graded as before. The over-all change in the patient was evaluated, both subjectively and objectively, as worse, no change, improved, or cured. A note was made on whether the patient had taken all his pills and whether he had remained at work and on the number of days lost, if any. All these entries could be recorded on the study form simply by circling the appropriate finding under each heading.

\section{Analysis of Results}

Almost 2,000 individuals with acute upper respiratory infections between January and May, 1956, were used in the study. A small number were dropped for failure to report back on the third day, and a few study forms were not completely filled out, but the over 1,900 observations reported under all headings were a more than adequate sample to demonstrate any significant differences that might be produced by the drugs. The coded findings on each case were punched on IBM cards, which were then sorted by test group. These were tabulated for each observation and the distributions percentaged or converted to means. (Where appreciable differences in percentages or means were found, tests for statistical significance were made, using a chi-square test for percentage variations and a t-test for evaluating differences in means. Because of the many observations compared, differences were not considered significant unless the chance probability was $1 \%$ or less.)

Table 1 shows the distribution of the eight treatment groups by age and sex. The small differences noted were all accounted for by random sampling variation, and there were no statistically significant differences. The comparability of mean number of colds per year shown in this table indicates that the groups were also random with regard to patients' susceptibility to colds. These eight groups were com- 
TABLE 4.-Decrease in Symptoms by Drug Groups

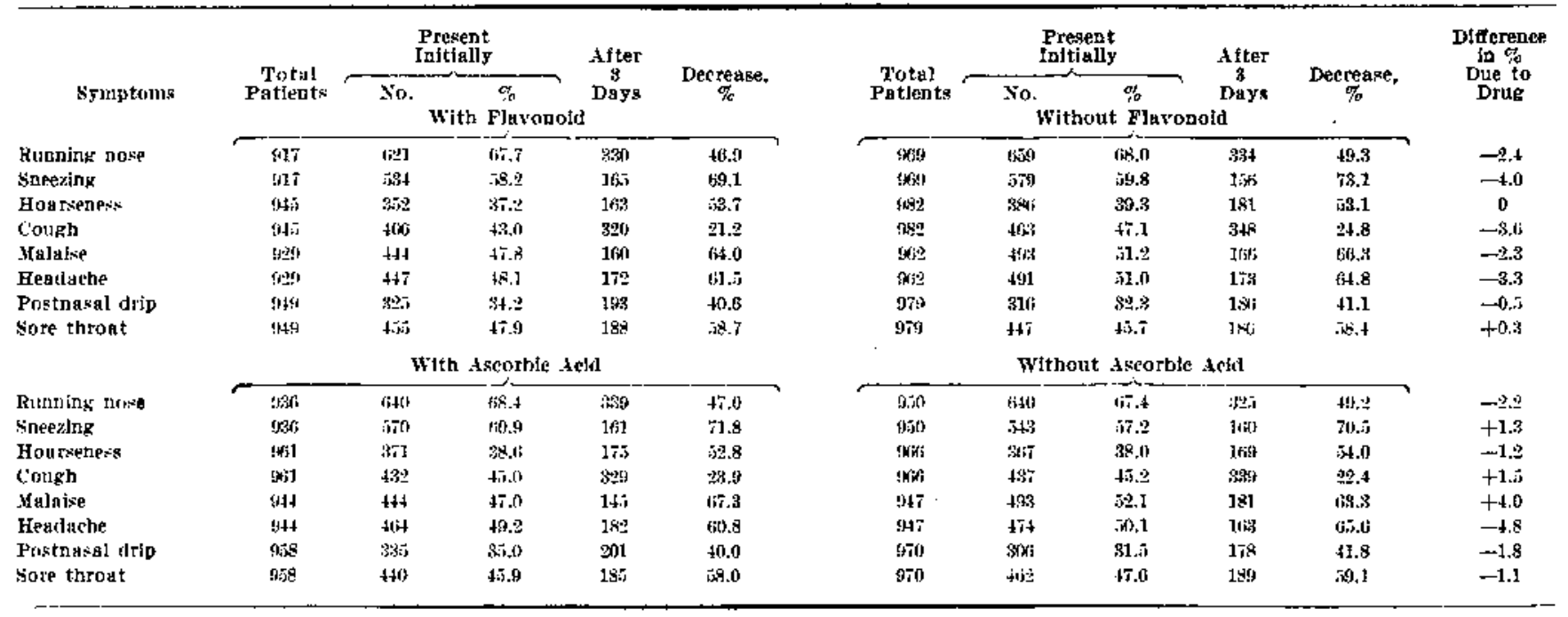

bined into two groups representing the patients receiving and not receiving bioflavonoids, and also the two different groups that did and did not receive ascorbic acid. The following tabulations are presented for all these combinations. Table 2 gives further evidence of the statistical comparability of the groups. The percentage of patients with pharyngotonsillitis and tracheobronchitis was not significantly different from group to group. Roughly the same proportion of patients required additional medicaments in each group, including antibiotics, nasal decongestants, and cough medicine, in addition to the medicaments under test, and none of these additional medicaments was given in a high enough percentage of cases to have seriously influenced the results of the study. The proportion of patients who did not take all their pills also did not vary significantly between groups. Cross tabulations (not shown) of all these factors against subjective and objective improvement indicated that the elimination of patients who received supplementary medicaments or did not take all their pills would not have appreciably affected the results of the study.

Table 3 shows the effect of bioflavonoid and ascorbic acid on the improvement after three days, judged by both the patient and the clinician. The distributions with and without each of the drugs are almost identical, for both subjective and objective change, with absolutely no statistically significant differences demonstrable. This is graphically illustrated in figure 2. The ameliorating effects of the two drugs on the patients' symptoms are evaluated in table 4 . It will be noted that on initial examination the percentage of patients in each group having each symptom was strictly comparable. The number of patients having the symptoms at the end of three days was then tabulated, and the percentage decrease, based on the number originally reported, was calculated. In a few instances patients developed symptoms after the first visit, but these cases were canceled by others in which the symptoms disappeared, and the number in any event was too small to affect the statistical significance of the data. The difference in percentage decrease that might be attributable to drug effect is shown in the right-hand column. It clearly indicates that neither bioflavonoid nor ascorbic acid had more than a random effect on any of the symptoms of the patients.

The effect of the two drugs on nasal secretions is shown in table 5. Again the initial distributions are well within random limits. There is a noticeable drop in the percentage with mucoid secretions after three days, but this change is almost identical in the groups receiving and not receiving both bioflavonoid and ascorbic acid. There is an actual increase in the per-

TABLE 5.-Change in Nasal Secretions by Drug Groups

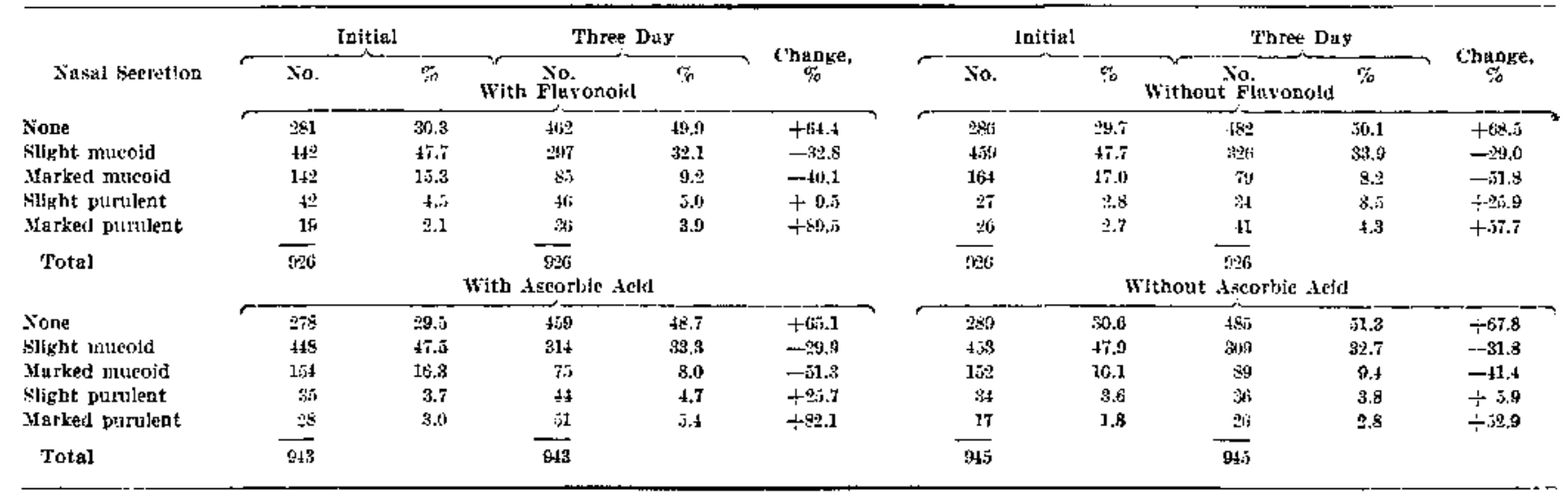




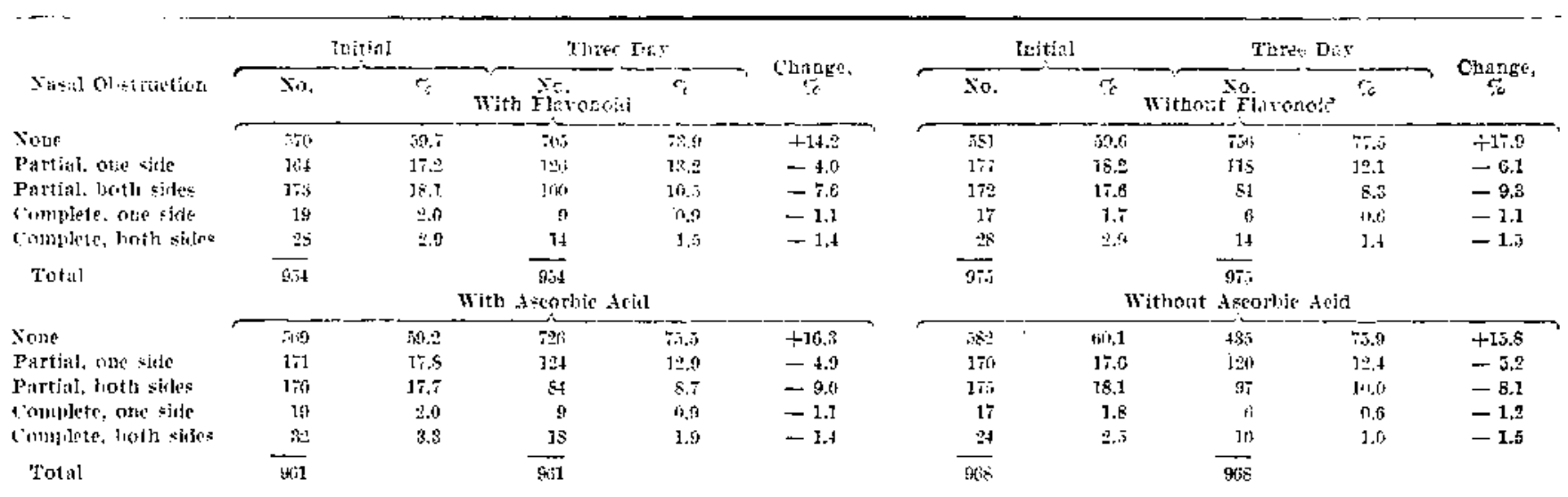

centage of patients having purulent nasal discharges, probably representing the development of secondary bacterial infection, but once more no significant effect on this phenomenon can be attributed to the drugs being tested. The changes in nasal obstruction in the course of the respiratory diseases are tabulated in table 6 . The distribution by degree of obstruction was almost identical before treatment in the test groups. There was a uniform decrease in the amount of obstruction in all groups, with no significant differences attributable to either of the drugs.

In table 7, the amount and severity of the pharyngitis found is tabulated. Again there were no appreciable differences in the distributions before therapy. There was a uniform decrease in the amount of pharyngitis found after three days, with neither of the changes in distribution exhibiting more than random variation.

Although this study was designed for outpatient follow-up, it was felt that the disposition and lost time might shed some light on the function of the drugs. Table 8 indicates that there has been no effect on these factors. The proportion of subjects sent home from work on the first visit could not be attributed to drug effect, but the uniformity noted is another indication of the comparability of the groups with regard to severity of infection. The percentage sent home on a subsequent visit might be an inverse index of the efficacy of the medication, but again there was no appreciable variation. The mean number of days lost, which would be a function of both initial severity and drug effectiveness, also showed no statistically significant differences.
On the theory that the effect of the drugs on capillary permeability might only be beneficial if they were given at the start of the illness, the data on patients treated within 24 hours of the development of symptoms were sorted out and tabulated in table 9 for subjective and objective change after three days. Not only was no difference of effect noticed between the patients who did or did not receive either of the drugs, but the distribution by improvement did not differ significantly from that in the total number of patients, regardless of the number of days since onset (table 3).

Since the study was conducted in the dispensaries or offices under the supervision of three different physicians, it was considered advisable to evaluate some of the findings in each separately, to determine whether any had achieved significantly different results than the others. This analysis for subjective change is shown in table 10 . It will be noted that the distributions are noticeably different under the three auspices, with statistical significance at well beyond the $0.1 \%$ level between all of them. This is due either to variation among the institutions in the standards for determining the subjective changes or to factors in the composition of the groups or the collateral treatment, such as the inclusion of students and private patients. The locality and the infecting organism may also be a factor. It is interesting, also, that all areas of the United States were included in this study. That it was not due to either bioflavonoid or ascorbic acid is evident from the fact that, despite wide variation in distribution between institutional groups, there were no statistically significant differences due

TABLE 7.-Decrease in Pharyngitis by Drug Groups

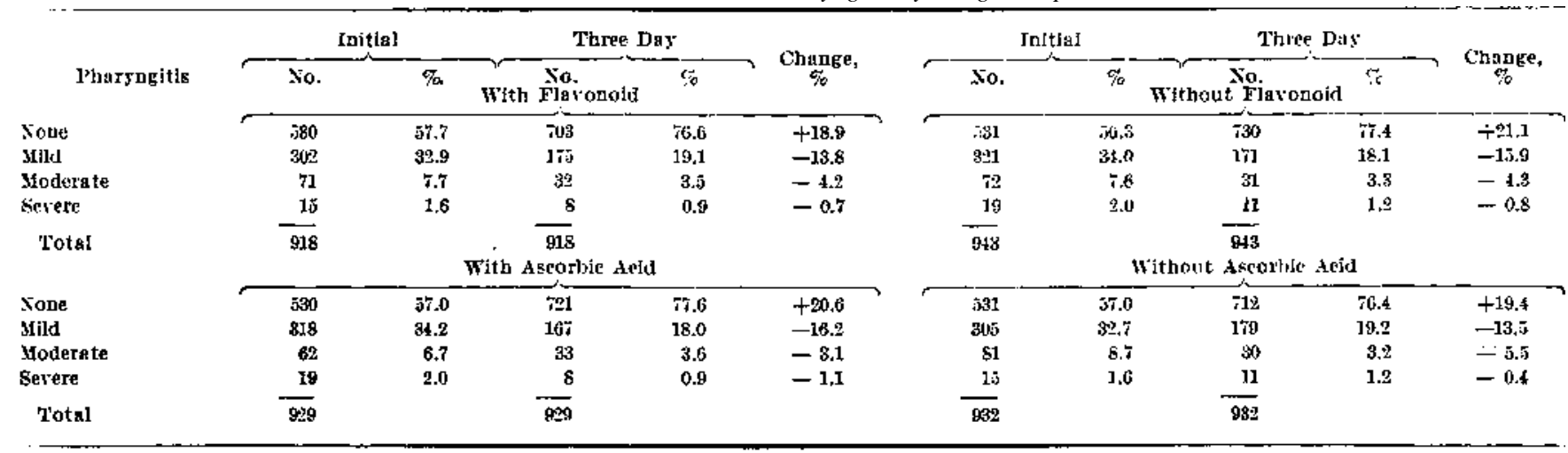


to the two drugs within any of the groups. The percentage differences noted, particularly in the PrattWhitney group, are still within the limits of random variation for a group of this size.

When the study had been running for several months, a preliminary check on the cases already reported indicated no effect from the bioflavonoids. On

TABLE 8.-Disposition of Cases and Mean Number of Work Days Lost by Drug Groups

\begin{tabular}{|c|c|c|c|c|c|c|c|c|}
\hline \multirow{3}{*}{$\begin{array}{c}\text { Disprsitio' } \\
\text { of cazes } \\
\text { hept at work }\end{array}$} & \multicolumn{4}{|c|}{ Binlluxntoid } & \multicolumn{4}{|c|}{ Aseorble Aejt } \\
\hline & \multicolumn{2}{|c|}{ Wuth } & \multicolumn{2}{|c|}{ With(st) } & \multicolumn{2}{|c|}{ witls } & \multicolumn{2}{|c|}{ Wthont } \\
\hline & $\begin{array}{l}\text { So. } \\
\text { Slifi }\end{array}$ & $\frac{\pi}{87.4}$ & No. & 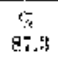 & No. & 8 & $\begin{array}{l}\text { Non. } \\
\text { stoxi }\end{array}$ & 管 \\
\hline $\begin{array}{l}\text { Seat home alter } \\
\text { flret rist }\end{array}$ & 78 & 8.2 & 83 & S.s & $\gamma^{\underline{q}}$ & $i .7$ & 87 & 0.3 \\
\hline $\begin{array}{l}\text { Sint houk on } \\
\text { subbequent risit }\end{array}$ & +16 & 4.3 & $3 \overline{3}$ & 3.9 & 约 & $3 . \pi$ & 41 & 4.4 \\
\hline I'otal & 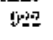 & & $9+19$ & & 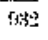 & & 031 & \\
\hline $\begin{array}{l}\text { Mean no. of work } \\
\text { days lont }\end{array}$ & & & & & & & & \\
\hline
\end{tabular}

the off chance that another compound might prove more effective, the medicaments were switched from lemon to orange flavonoid and the study continued. The difference in effect of these two products on subjective and objective change is shown in table 11. While the lack of effect is more evident in the lemon flavonoid group, the differences noted between the patients receiving and not receiving orange flavonoid did not reach statistical significance and can be completely accounted for by chance variation. It will be noted that the results with orange flavonoid were significantly worse than those obtained with the lemon flavonoid controls. This difference is probably due to a change in the severity of respiratory disease in the later months when the orange compound was being evaluated and emphasizes the importance of simultaneous controls as were used in this study.
The lack of difference cannot be attributed to the limitation to a single reobservation. In any drug influencing the course of an acute self-limited disease, some changes must be noticeable in at least some of the symptoms after three days or else the effect is so

TABLE 9.-Subjective and Objective Change in Patients Tieated in First Twenty-four Hours by Drug Groups

\begin{tabular}{|c|c|c|c|c|c|c|c|c|}
\hline \multirow{2}{*}{ • } & \multicolumn{4}{|c|}{ FJaronoja } & \multicolumn{4}{|c|}{ Ascorhie Acid } \\
\hline & \multicolumn{2}{|c|}{ With } & \multicolumn{2}{|c|}{ Without } & \multicolumn{2}{|c|}{ With } & \multicolumn{2}{|c|}{ Without } \\
\hline Change & No. & 50 & No. & $\%$ & No. & $\%$ & No. & F \\
\hline $\begin{array}{c}\text { Sulpjectire } \\
\text { Forwe }\end{array}$ & in & II. 2 & (31 & 11.5 & $\mathrm{t}+3$ & 11.1 & wit & 11.6 \\
\hline Sone & i & 21.6 & $11: 3$ & 91.3 & $1 \% 2$ & $\unrhd 1.8$ & 116 & SI.1 \\
\hline [mprovel & \pm+1 & $\$ 1,4 i$ & 215 & 40.5 & 290 & +2.1 & 200 & 40.0 \\
\hline C'uret & 145 & siti & $1+2$ & 3il. $\overline{7}$ & 140 & 30 & 150 & 97.3 \\
\hline Toutul & 沙儌 & & 121 & & 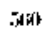 & & 5.50 & \\
\hline Ohjeetive & & & & & & & & \\
\hline Wores & 41 & 7.4 & 49 & 0.4 & tis & 8.5 & $H$ & 8.2 \\
\hline Sone & $11 \ddot{-\mu}$ & 20.1 & $8 \bar{i}$ & 16.7 & $10 y$ & 18.4 & (9) & 18.5 \\
\hline Improsing & -3 & tin, & 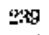 & 45.5 & $\underline{y}$ it & 46.7 & ats & $14 . j \mathrm{j}$ \\
\hline C'med & 1.1 & 27,1 & 367 & בxy & $1+4$ & $2 f 5.3$ & 1) & 28.8 \\
\hline Total & ijf & & ige & & intt & & 35 & \\
\hline
\end{tabular}

negligible that it can be completely discounted. The procedure used did not evaluate the effectiveness of either of the drugs in preventing secondary bacterial infections and other complications, for which a minimum of a second reexamination after one week would have been necessary, because it had been designed to test the claim that the bioflavonoids, in conjunction with ascorbic acid, aborted or cured the common cold. Neither did it evaluate the use of these vitamins in prophylaxis against the common cold.

The study cannot be invalidated on the basis of too high a percentage of placebo reactors. It is well known that the majority of common colds are alleviated to some extent by the administration of any symptomatic therapy, and the improvement noted in the over 1,900

TABLE 10.-Subjective Change by Study Groups

\begin{tabular}{|c|c|c|c|c|c|c|c|c|c|c|c|c|}
\hline \multirow[b]{3}{*}{$\begin{array}{l}\text { Thunge: } \\
\text { Elayonoid }\end{array}$} & \multicolumn{4}{|c|}{ Tohirock } & \multicolumn{4}{|c|}{ Ariulnio } & \multicolumn{4}{|c|}{ dohnstor } \\
\hline & \multicolumn{2}{|c|}{ With } & \multicolumn{2}{|c|}{ Withour } & \multicolumn{2}{|c|}{ with } & \multicolumn{2}{|c|}{ Without } & \multicolumn{2}{|c|}{ With } & \multicolumn{2}{|c|}{ Without } \\
\hline & No. & sis & Sn. & $\because 6$ & Nis. & $\%$ & No. & $\%$ & No. & $\%$ & So. & $\%$ \\
\hline Worse & 91 & $12 . \bar{t}$ & ]n: & 13.9 & 0 & n & 1 & 11.9 & 21 & 15,6 & $1 ;$ & 18,3 \\
\hline Nont & $1, \pi=1$ & 201.6 & 14.5 & $1: B, f_{2}$ & 然 & 32.1 & 㐘 & s.t.t & : 311 & $\underline{2} \therefore$ & +2 & ב \\
\hline [murencel] & 3 & $10 . \mathrm{s}$ & sil: & +10.1 & $.16 i$ & $+\underline{t}, \underline{\underline{1}} \mathrm{I}$ & in & $4 \bar{i}, 4$ & 政 & 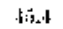 & 1.1 & $: 88.8$ \\
\hline ('tired & Ifin; & trat.1 & $\mathrm{T} ! k^{\prime}$ & Lis: & $2 x$ & 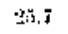 & $3 x$ & 26,3 & 2.1 & 11,8 & I! & $\ln 6$ \\
\hline l'ottal & $51 \%$ & & 7.11 & & 309 & & 114 & & $\$ t 0$ & & $11: 3$ & \\
\hline \multicolumn{13}{|l|}{ Atsorbile tcis } \\
\hline Worke & $\{1,2$ & $1 \geq .7$ & $1+1+3$ & $13: \%$ & 0 & at & 1 & $(1.9)$ & 1: & 1‥: & 11 & 1s.1 \\
\hline Sone & 148 & $11, \mathrm{ti}$ & 137 & 21.7 & $3 ;$ & 32.1 & 出 & E-i.t & 17 & 10.7 & $2 . i$ & 21.6 \\
\hline [mprascel & is:-2 & 4.1 .1 & $\underline{s}$ & $30 . \overline{1}$ & $\sqrt{1}$ & 13.1 & is & wi. $\pi$ & $\$ 1$ & :3, & $\pi$ & $+0,1$ \\
\hline inreal & $17 * 2$ & 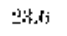 & $1 \times:$ & $2 \pi, 1$ & 27 & 29.8 & 31 & $2-2.2$ & $3:$ & 11.2 & 12 & 11.2 \\
\hline Totul & ה & & $7 \cdot 20$ & & 1019 & & ilt & & $116 i$ & & Ilo & \\
\hline
\end{tabular}

\section{Comment}

The overwhelming impression gained from all these data is the singular lack of effect produced by either the bioflavonoid or the ascorbic acid. If any real clinical response were produced by either of these drugs in even an appreciable minority of the patients treated with them, significant statistical differences should have been evident in at least some of the factors observed. This is particularly so because of the large sample size and the exact comparability of the test groups for all observed factors at the start. cases is about what one would expect after three days of such therapy. For the claims for the drugs being tested to be substantiated, there would have to have been present an effect over and above that found for the entire group, and this difference was completely lacking.

It will be noted that no analyses were performed on the individual drug groups to evaluate synergism or antagonism. In the absence of any differences between the combined groups specific for bioflavonoid and for ascorbic acid (see section on methodology), 
it seemed necessary to look for such effects. It is statistically possible for two drugs to both have a beneficial effect but to be completely antagonistic and cancel each other, in which case the analysis used would yield a false-negative result. An unusual effect

TABLE 11.-Difference Between Lemon and Orange Flavonoid

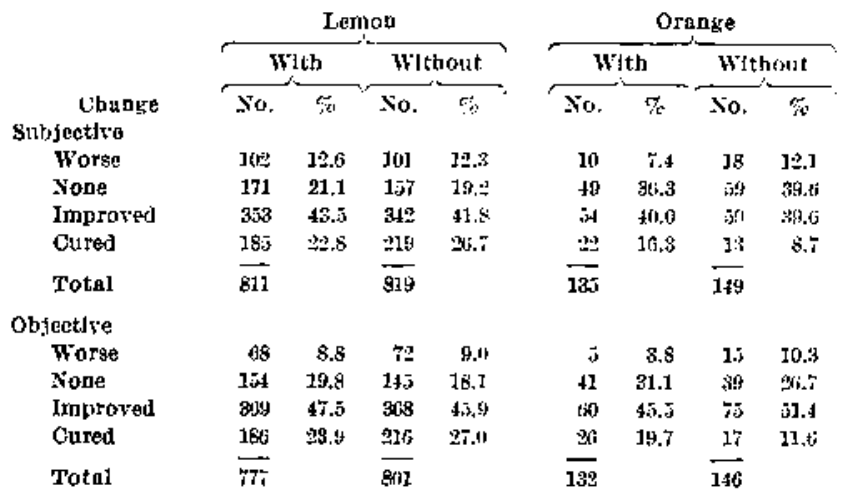

of this kind, however, would be immediately apparent by simple inspection of the data at the time the groups were combined, and it was not noted.

Thus far there is no convincing evidence that bioflavonoids or ascorbic acid can alleviate a cold when used alone or in combination with other therapies, and our evidence confirms the conviction that bioflavonoids or ascorbic acid are without specific effect in such conditions. Although some might argue that much higher doses of either bioflavonoids or ascorbic acid are necessary to demonstrate a curative effect, we emphasize that the patients in this study received $200 \mathrm{mg}$. of ascorbic acid and $1 \mathrm{gm}$. of bioflavonoid per day, levels generally considered adequate to affect the capillary permeability. Since the usefulness of these compounds in reducing capillary fragility has gener- ally been applied to long-standing conditions, there is no reason to believe that massive doses would achieve the rapid effect necessary in conditions as acute as a cold.

\section{Summary}

The effect of $1 \mathrm{gm}$. of bioflavonoid and/or $200 \mathrm{mg}$. of ascorbic acid administered daily in aborting or curing the common cold was tested in a controlled double-blind trial on over 1,900 subjects. The medicaments were given, either singly or in combination, in addition to the usual treatment used to alleviate symptoms. No appreciable effects were observed after three days on subjective or objective improvement; on disappearance of running nose, sneezing, cough, hoarseness, malaise, headache, postnasal drip, or sore throat; on decrease in nasal secretions or obstruction or pharyngitis; or in time lost from work. In our opinion neither of these drugs in the dosage given has any significant effect in altering the course of the common cold.

1740 Broadway (Dr. Tebrock).

The following doctors from the staff of Sylvania Electric Products, Inc., recorded and commented on the clinical observations used in this study: William Young, Hilton Lopez, Manuel Kaufman, Thomas Foote, C. Stafford Clay, William H. Regelman, Russell Pfeil, Jerome Paparella, Charles Youngman, S. C. Bower, George Means, S. Gardner, Edwin Reynolds, Cornelius Driscoll, Emil Bove, Charles Fleck, Paul Gallaher, Carl Lohmann, Joseph Zavisca, George Cody, and Quay McCune.

\section{References}

1. Brewster, J. M.: Antihistaminic Drugs in Therapy of Common Cold, Indust. Med. 18: 217-220 (May) 1949.

2. Brody, H. D.: Ascorbic Acid and the Common Cold, Studied Opinion, J. Am. Dietet. A. 29: 588 (June) 1953.

3. Martin, G. J.: Biochemistry of Bioflavonoids, Ann. New York Acad. Sc. 61:646-651 (July 8) 1955 .

4. Sokoloff, B.: Capillary Syndrome in Viral Infections: Treatment with Citrus Flavonoids, Am. J. Digest. Dis. 22: 7-9 (Jan.) 1955. Biskind, M. S., and Martin, W. C.: Use of Citrus Flavonoids in Respiratory Infections, ibid. 21: 177 (July) 1954; Use of Citrus Flavonoids in Infections II, ibid. 22: 41-45 (Feb.) 1955. Sokoloff, B.; Biskind, M. S.; Martin, W. C., and Saelhof, C. C.: On Therapeutic Use of Citrus Bio-Flavonoids, Clin. Med. 2: 787-792 (Aug.) 1955. 